\title{
New insights in pathophysiology of cardiovascular benefits after obesity surgery
}

\author{
Stefano Ministrini, Giulia Mondovecchio, Graziana Lupattelli \\ Internal Medicine, Department of Medicine, Università degli Studi di Perugia, Italy
}

RELATED ARTICLE

Kaya and Elkan, see p. 674
Correspondence to:

Stefano Ministrini, MD, Department of Medicine, Università degli Studi di Perugia, Piazzale Gambuli, 1-06129, Perugia (PG), Italy, phone: +390755784020, email: stefano. ministrini@studenti.unipg.it Received: June 7, 2020. Accepted: June 8, 2020. Published online: August 25, 2020. Kardiol Pol. 2020; 78 (7-8): 657-658 doi:10.33963/KP.15561 Copyright by the Author(s), 2020
Obesity is an established risk factor for a large variety of chronic disorders, leading to severe disability and early mortality. ${ }^{1}$ Among them, cardiovascular disease (CVD) has the heaviest impact on disability and mortality. The relationship between obesity and CVD is mediated by other major cardiovascular risk factors, such as hypertension, diabetes, dyslipidemia, and metabolic syndrome. ${ }^{2}$ However, the relationship between obesity and CVD goes beyond the effect of established cardiovascular risk factors. Indeed, severe obesity is associated with other atherosclerosis promoting factors, such as prothrombotic state, low-grade chronic inflammation, ${ }^{3}$ microcirculatory dysfunction, ${ }^{4}$ and obesity-related myocardial dysfunction. ${ }^{5}$

Significant weight loss is the mainstay in the treatment of severe obesity in order to achieve a reduction in obesity-related morbidity and mortality. Bariatric surgery techniques, and especially laparoscopic sleeve gastrectomy (LSG), have been proven to achieve a significant weight loss, with associated reduction of obesity-related disability and mortality. ${ }^{6}$ Nonetheless, the benefits of bariatric surgery on cardio-metabolic risk factors and markers of early cardiovascular damage seem to overcome the effects of weight loss only. ${ }^{7}$ It has been hypothesized that bariatric surgery could act on insulin-resistance, ${ }^{7}$ microcirculatory dysfunction, ${ }^{4}$ chronic low-grade inflammation, and adipokine profile ${ }^{8}$ in a weight loss-independent manner.

Kaya and Elkan, in their article "The impact of weight loss after laparoscopic sleeve gastrectomy on early markers of atherosclerotic vascular disease: a prospective study" in this issue of Kardiologia Polska (Kardiol Pol, Polish Heart Journal) went to further confirm that
LSG can lead to a significant improvement in surrogate markers of atherosclerotic vascular disease. ${ }^{9}$ In our opinion, their most relevant result was the correlation between the increase of aortic propagation velocity (APV) and other markers of preclinical atherosclerosis, namely ankle-brachial index and carotid intima-media thickness. APV is an emerging and promising bedside tool for the prediction of CVD and it reflects the changes of arterial wall thickness and stiffness. ${ }^{10}$ This result gives further support to the hypothesis that large artery stiffening is involved in the pathophysiology of obesityrelated CVD. ${ }^{11}$

Another interesting observation is the association between the reduction of epicardial fat thickness and the reduction of APV. Visceral fat is a key factor in several metabolic and cardiovascular disorders in severe obesity due to its high metabolic and endocrine activity. ${ }^{12,13}$ Visceral fat designates the adipose tissue surrounding abdominal organs and the heart, the latter further divided in epicardial and pericardial fat. Both pericardial and epicardial fat thickness are associated with insulin resistance, ${ }^{14}$ and left ventricular hypertrophy and dysfunction, ${ }^{15}$ both in obese and normal-weight subjects.

In conclusion, this paper significantly contributes to a growing body of evidence that LSG for the treatment of obesity has several beneficial effects on body composition and cardiovascular physiology with a positive drawback in terms of CVD related disability and mortality. Since the exact pathophysiological mechanisms underlying these effects are still poorly understood, works like the one of Kaya and Elkan are improving our knowledge about this topic. 


\section{ARTICLE INFORMATION}

DISCLAIMER The opinions expressed by the author are not necessarily those of the journal editors, Polish Cardiac Society, or publisher.

CONFLICT OF INTEREST None declared.

OPEN ACCESS This is an Open Access article distributed under the terms of the Creative Commons Attribution-NonCommercial-NoDerivatives $4.0 \mathrm{In}$ ternational License (CC BY-NC-ND 4.0), allowing third parties to download articles and share them with others, provided the original work is properly cited, not changed in any way, distributed under the same license, and used for noncommercial purposes only. For commercial use, please contact the journal office at kardiologiapolska@ptkardio.pl.

HOW TO CITE Ministrini S, Mondovecchio G, Lupattelli G. New insights in pathophysiology of cardiovascular benefits after obesity surgery. Kardiol Pol. 2020; 130: 657-658. doi:10.33963/KP.15561

\section{REFERENCES}

1 Ricci MA, De Vuono S, Scavizzi M, et al. Facing morbid obesity: how to approach it. Angiology. 2016; 67: 391-397.

2 Csige I, Ujvárosy D, Szabó Z, et al. The Impact of obesity on the cardiovascular system. J Diabetes Res. 2018; 3407306.

3 Samad F, Ruf W. Inflammation, obesity, and thrombosis. Blood. 2013; 122: 3415-3422.

4 Ministrini S, Fattori C, Ricci MA, et al. Microcirculatory improvement induced by laparoscopic sleeve gastrectomy is related to insulin sensitivity retrieval. Obes Surg. 2018; 28: 3151-3158.

5 Ricci MA, De Vuono S, Pucci G, et al. Determinants of low levels of brain natriuretic peptide in morbid obesity. Clin Nutr. 2017; 36: 1075-1081.

6 Sjöström L. Review of the key results from the Swedish Obese Subjects (SOS) trial-a prospective controlled intervention study of bariatric surgery. J Intern Med. 2013; 273: 219-234.

7 Ricci MA, Ministrini S, De Vuono S, et al. Sleeve gastrectomy efficacy on metabolic and cardiovascular dysfunction with a focus on the role of comorbidities. Angiology. 2018; 69: 475-482.

8 Ministrini S, Ricci MA, Nulli Migliola E, et al. Chemerin predicts carotid intima-media thickening in severe obesity. Eur J Clin Invest. 2020; e13256.

9 Kaya BC, Elkan H. The impact of weight loss after laparoscopic sleeve gastrectomy on early markers of atherosclerotic vascular disease: a prospective study. Kardiol Pol. 2020; 130: 674-680.

10 Ghaderi F, Samim H, Keihanian F, Danesh Sani SA. The predictive role of aortic propagation velocity for coronary artery disease. BMC Cardiovasc Disord. 2018; 18: 121.

11 Tarnoki AD, Tarnoki DL, Bogl LH, et al. Association of body mass index with arterial stiffness and blood pressure components: a twin study. Atherosclerosis. 2013; 229: 388-395

12 Ministrini S, Ricci MA, Daviddi G, et al. Determinants of high parathyroid hormone levels in patients with severe obesity and their relationship with the cardiometabolic risk factors, before and after a laparoscopic sleeve gastrectomy intervention. Obes Surg. 2020; 30: 2225-2232.

13 Ricci MA, Scavizzi M, Ministrini S, et al. Morbid obesity and hypertension: the role of perirenal fat. J Clin Hypertens (Greenwich). 2018; 20: 1430-1437.

14 Liu J, Song G, Meng T, Zhao G. Epicardial adipose tissue thickness as a potential predictor of gestational diabetes mellitus: a prospective cohort study. BMC Cardiovasc Disord. 2020; 20: 184.

15 Pucci G, Battista F, de Vuono S, et al. Pericardial fat, insulin resistance, and left ventricular structure and function in morbid obesity. Nutr Metab Cardiovasc Dis. 2014; 24: 440-446. 